\title{
LAS ALIANZAS DEL AZÚCAR Y LA POLÍTICA: APUNTES PARA LA COMPRENSIÓN HISTÓRICA DE LA ÉLITE AZUCARERA EN COSTA RICA (1950-2010)
}

\author{
Jorge Marchena Sanabria
}

\author{
Recibido: 01/02/2015 Aceptado: 16/10/2015
}

\begin{abstract}
Resumen
En este artículo se analizan los nexos políticos-empresariales que se han constituido entre los ingenios azucareros guanacastecos y el Estado costarricense. El objetivo principal consiste en explicar el proceso por el cual sus dueños -las familias Arias, Sánchez, Jenkins y Dobles, para citar las principales- habían colocado a sus miembros en posiciones centrales dentro del Partido Liberación Nacional y la política costarricense; además de analizar el papel de poderosos grupos mediáticos, empresariales y políticos de la región centroamericana. La metodología básicamente consistió en una reconstrucción histórica de los orígenes, propietarios, accionistas y vínculos políticos de cada una de las empresas estudiadas.

Palabras clave: élites; ingenios azucareros; política; clientelismo; democracia.

Abstract

This article analyzes the political-business links between the Guanacaste sugar mills and the Costa Rican government. The main objective was to explain the process by which its owners -families Arias, Sánchez, Jenkins and Dobles, to cite the main-, had placed its members in central positions within the National Liberation Party and Costa Rican politics, in addition to analyzing the powerful role of media groups, business and politicians in Central America. The methodology consisted of a historical reconstruction of the origins, owners, shareholders and political ties of each of the companies studied.
\end{abstract}

Key words: elites; sugar mills; politics, clientelism; democracy.

\section{Introducción}

Muchos costarricenses conocen que la familia Sánchez es propietaria del Ingenio Taboga, que posee una fortuna considerable y que ha estado fuertemente asociada a la política nacional. Ya se han escrito diversas notas biográficas acerca de algunos miembros de este clan herediano, incluso se han realizado documentales de televisión transmitidos en tiempos de campañas electorales. Sin embargo, 
toda esta información es superficial, fácilmente rastreable mediante una búsqueda en periódicos o en internet. Poco se dice de las conexiones empresariales y redes de poder que han tejido las familias Arias y Sánchez, así como sus aliados Jenkins, Jiménez y otros, en su afán de posicionar sus negocios de la mejor manera y acumular mayor poder e injerencia política.

Este artículo no pretende reconstruir de forma genealógica la trayectoria y vida de ciertos miembros de las familias citadas, pues su objetivo radica en explicar cómo se conformó históricamente la riqueza de un grupo de empresarios azucareros a lo largo del siglo XX. Para ello, se recurrió a un marco teórico afín a los estudios del poder, ${ }^{1}$ con enfoque en la idea de que estos eran grupos o élites de nivel provincial, los cuales fortalecieron sus posiciones económicas y gradualmente incursionaron en el mundo político, a través de conspicuas alianzas con otras facciones tanto nacionales como centroamericanas,.

Antes de ahondar en la temática, se debe explicar el funcionamiento general del negocio cañero y sus principales productos, como el azúcar blanco centrifugado, que tiene dos grandes destinatarios: el uso industrial (empleado en confites, galletas, repostería, bebidas, aderezos, entre otros) y el consumo diario. A estos se agregan la fabricación de melaza para los alcoholes, el etanol y el bagazo para la producción eléctrica entre los usos más importantes en Costa Rica (Subirós, 2000). El grueso de la producción se destina al mercado local (aproximadamente el 60 por ciento) y el restante se exporta a mercados foráneos, en especial el azúcar sin refinar o el etanol. Los cuatro ingenios de la cuenca del Tempisque, Taboga, El Viejo, Central Azucarera del Tempisque S.A. y El Palmar producen hasta el 65 por ciento de la caña nacional (Liga Agrícola e Industrial de la Caña de Azúcar, 2012).

Asimismo, el gremio mantiene el monopolio absoluto en Costa Rica a través de la Liga Agrícola e Industrial de la Caña de Azúcar (LAICA), ya que gracias a esta entidad han perdurado férreos controles estatales contra la importación de azúcares y afines. También, la Liga ha asegurado beneficios tales como un notorio apoyo del aparato público en exención arancelaria para la importación de maquinaria agroindustrial, apoyo crediticio por parte del Sistema Bancario Nacional, la construcción de un muelle exclusivo para la exportación azucarera (Punta Morales en Puntarenas) y, además, ha conquistado un sitial de honor en la discusión de los tratados de libre comercio de las últimas dos décadas.

El azúcar blanco de mesa, como tal, es un producto en apariencia "débil". A nivel mundial cuenta con una inmensa competencia contra los endulzantes artificiales (u otros de origen natural extraídos del maíz o de la remolacha), una producción de millones de toneladas anuales y aranceles de importación exorbitantes. Aun así, el gremio nacional reporta ganancias cercanas a los \$200 millones procedentes del azúcar, alcohol y melaza (Liga Agrícola e Industrial de la Caña de Azúcar, 2012). ¿Cómo se puede explicar esta aparente contradicción? En el párrafo anterior se encuentra-de forma 
implícita- parte de la respuesta. El gremio cuenta con un mercado interno cautivo (en la práctica controlado por un oligopolio), el conspicuo apoyo del aparato estatal a lo largo de varias décadas ${ }^{2}$ y para asegurar estos dos puntos, se han construido redes de poder entre el empresariado y los partidos políticos, especialmente Liberación Nacional. Por tanto, este último punto es, en esencia, el eje central del presente artículo.

En las páginas siguientes se revisarán algunos de los nexos entre los grandes ingenios guanacastecos y la política costarricense (inclusive la centroamericana), con la finalidad de percibir la complejidad que envuelve al microcosmos azucarero. También se recapitulan sus antecedentes generales para enfatizar que las relaciones entre haciendas guanacastecas y los grupos de poder no son nuevas.

Asimismo, para esto se utilizó un amplio abanico de fuentes, desde periódicos hasta documentos del Registro Nacional, bibliografía, documentos de archivos, entre otros. Por su parte, el artículo se divide en dos grandes partes, la primera enfocada en los ingenios estudiados: Taboga y El Viejo; y la otra revisa la influencia azucarera en las campañas electorales recientes.

\section{El Viejo y sus relaciones con latifundistas, dictadores, azucareros y turistas}

El caso del ingenio El Viejo está marcado por una larga sucesión de célebres propietarios que se extiende desde la Colonia hasta mediados del siglo XX. Aunque su rol político directo es menor que el de Taboga, su papel resulta fundamental, pues en las últimas décadas del siglo XX y primeras del XXI, se ha convertido en su principal aliado. Ante esto, en las siguientes líneas se pretende explicar el origen y algunos vaivenes de esa relación.

Rápidamente, se puede anotar que en la época colonial, la Hacienda El Viejo fue una cofradía, tras la Independencia en 1821 continuó con dicho estatus y en 1846, fue expropiada por el Gobierno. En la década de 1870, fue disputada por la familia Giralt y vecinos de la localidad que la exigían como terrenos comunales. Así pues, en última instancia, los Giralt se aseguraron la posesión de la hacienda. A finales de ese siglo y principios del XX, pasó a manos de Laura y Alfonso Salazar Aguilar, ganaderos y nietos de un militar de origen nicaragüense (Cabrera, 2007).

En 1926, Alfonso cedió sus terrenos al notorio latifundista David Stewart (también conocido como George Wilson), con quien había formado una sociedad tres años atrás. Finalmente, en 1944, Wilson dividió las tierras en 44 partes, tres de las cuales vendió a la sociedad Pinto-Gutiérrez, formada por el connotado médico josefino Dr. Fernando Pinto Echeverría y los hermanos Carlos Manuel (también médico), Marta y Margarita Gutiérrez Cañas. Esta última contrajo nupcias con Alberto Pinto Echeverría, hermano de Fernando.

La carrera de Pinto fue muy destacada, pues desempeñó importantes cargos públicos como delegado costarricense ante la recién creada Organización de las Naciones 
Unidas, fue miembro de la Cámara de Ganaderos, presidente del Club Unión del Partido Unión Nacional y formó parte de la Junta Directiva del periódico La Nación, así como de la histórica Asamblea Constituyente de 1949 ("Duelos sociales. Dr. Don Fernando Pinto E." 1957).

La familia Pinto tenía importantes terrenos en Cartago, sobre todo en Turrialba, donde ya se desarrollaron cultivos de café y caña. A su muerte, en 1957, el ingenio apenas estaba siendo construido y su herencia pasó a manos de su extensa familia; así, muchas de las acciones de la nueva azucarera terminaron en manos de su esposa, Carmen López Borbón.

Dado que un ingenio azucarero es extremadamente costoso, los Pinto optaron por vender partes de la hacienda para completar el proyecto. Así, en la década de los sesenta, la planta estuvo controlada por dos bloques emparentados, los Robles Guzmán y los Pinto, así como otros participantes.

Rodolfo Robles Guzmán -presidente de la Junta Directiva- y su hermana Carmen fueron hijos naturales de Alberto Pinto Fernández. Rodolfo se destacó en la vida pública como el fundador del Movimiento Costa Rica Libre, grupo de ultra derecha y rival acérrimo de los partidos e ideas comunistas que llegaban a Costa Rica en esa época. ${ }^{3}$ El otro grupo lo constituyó la viuda de Fernando Pinto y las hermanas Margarita y Thais Pinto, hijas de Alberto Pinto y Margarita Gutiérrez Cañas, quienes principalmente los cargos de vocales y el comité de vigilancia. Margarita Pinto había contraído matrimonio con el señor Carlos Federspiel Ullman, propietario de la Tienda Universal en San José, uno de los comercios más importantes del país. Su hijo político, Hubert Federspiel Kreutzwald, pasó a ocupar el puesto de gerente del ingenio (y de la tienda), y además fue considerado como un importante miembro derechista y amigo de los dictadores nicaragüenses; los Somoza.

$\mathrm{Su}$ amistad con esta familia nicaragüense no es un simple dato accesorio. De acuerdo con Edelman (1998), la familia Somoza había adquirido El Viejo junto con Teodoro Picado Lara (hijo del expresidente Picado) en el periodo 1940-1960. En este lapso, Alfonso Salazar Céspedes también figuraba como propietario, pues su familia era dueña de varias fincas en Guanacaste dedicadas principalmente a la ganadería, entre las que destacaba El Murciélago en La Cruz, la cual también contaba con la participación de Somoza (Ruiz, 1964). De esta forma, había tres grupos de dueños, puesto que Wilson había partido El Viejo en muchas fracciones, de las cuales solo algunas fueron adquiridas por los Pinto-Gutiérrez, mientras que Salazar compró otras fracciones sobrantes, al igual que Somoza.

Sin embargo, existieron otros nexos dignos de mención. Por ejemplo, el de Federspiel y Rodolfo Robles Guzmán, quienes eran considerados miembros de la ultra derecha. Por su parte, Picado también estuvo vinculado con Somoza y Salazar lo visitaba en la hacienda, por lo cual resulta claro que casi todos tenían en común una enemistad en distintos niveles con el Partido Liberación Nacional (PLN). Tan solo el 
caso de Somoza lo reflejaba perfectamente, pues en 1955 había apoyado y hospedado a las fuerzas invasoras, a cargo del Dr. Calderón Guardia, que pretendían derrocar a Figueres Ferrer.

En el ingenio no solo figuraban estos opositores a Liberación, también se incluían cubanos exiliados dirigidos por Jorge Rovira García, otro de los gerentes de la empresa y también gozaba de buena amistad con el dictador nicaragüense, del que aún hoy se narran sus peculiares visitas a la vieja casona de la hacienda y siempre era escoltado por más de una veintena de soldados de la Guardia Nacional (Edelman, 1994). Las leyendas populares también citan que la casona estaba repleta de cuartos secretos y túneles subterráneos que facilitarían el escape del dictador en caso de emergencia, pues sus rencillas con los liberacionistas eran bien conocidas. Tanto así, que en algún momento Luis Somoza pretendió donar la casona y varias hectáreas circundantes al Gobierno y convertirlo en un museo para apaciguar los ánimos costarricenses.

Sin embargo, la hacienda tuvo un viraje en 1974, cuando fue adquirida por Álvaro Jenkins Morales, un hombre nacido en Alajuela en 1923, hijo del señor Augusto Jenkins, reconocido personaje ramonense de origen inglés, propietario de la farmacia del pueblo durante la primera mitad del siglo XX y simpatizante del Ejército de Liberación Nacional en 1948. Álvaro Jenkins se formó como ingeniero mecánico y a partir de 1958 trabajó para el Ingenio Taboga, además de ser uno de sus accionistas.

En la industria citada ocupó los cargos de gerente y presidente hasta su salida en 1977, incluso representó a Taboga y a la Liga Agrícola e Industrial de la Caña de Azúcar (LAICA) durante la discusión de la reforma a la Ley de la Caña en 1971. También fue nombrado como ministro de Obras Públicas y Transportes durante la administración de su gran amigo Daniel Oduber y representante personal de este ante la Corporación Costarricense de Desarrollo (CODESA). En esta función jugó un papel fundamental como el arquitecto y uno de los principales impulsores de lo que sería la Central Azucarera del Tempisque S.A. (CATSA), para luego, entre 1978 y 1981, fungir como diputado liberacionista, e incluso como posible precandidato para la elecciones de 1978.

Jenkins adquirió el ingenio gracias a préstamos con el Banco Nacional; sin embargo, impresiona la manera en que desplazó a casi todos los accionistas anteriores, incluyendo a la familia Pinto, Federspiel y Salazar. Hasta la fecha, solo Jenkins y su familia son reconocidos públicamente como los propietarios de la azucarera. Esta información la contradice parcialmente Edelman (1998), quien apunta que Somoza sí se mantuvo dentro del grupo que controlaba la hacienda, lo cual podría afirmar que Jenkins obtuvo el ingenio, mientras que otros socios mantuvieron solamente las tierras: "Los sentimientos en contra de los Somoza se intensificaron en Costa Rica en 1978 (...) Somoza previó la expropiación de sus propiedades y calladamente renunció como presidente de El Viejo en agosto de 1978" (272). 
Lo anterior lleva a suponer que Jenkins y Somoza pudieron ser copropietarios de El Viejo o que el primero absorbió las tierras en posesión del nicaragüense; sin embargo, solo se tiene certeza de que la actual casona y otros dominios aledaños forman parte de la empresa turística Wild Wetlands Hacienda El Viejo (Aguilar, 2009), propiedad únicamente de Jenkins, con el empleo notorio de una fachada turística. Los rumores en los pueblos cercanos al ingenio indican solo dos aspectos: uno, que Jenkins es el propietario actual, insinuando que removió a Somoza; y segundo, que Daniel Oduber también pudo haber sido un dueño de El Viejo, al menos temporalmente, o que tal vez apoyó a Jenkins para que lo adquiriera. ${ }^{4}$

Indudablemente, Jenkins, con el favor del PLN, elevó el nivel del ingenio y ya para finales de los años ochenta, éste se encontraba bien posicionado entre los cuatro grandes del gremio. Tras su renuncia al Congreso, Jenkins Morales únicamente conquistó cargos dentro de la Junta Directiva de LAICA, mientras que su hijo José Álvaro Jenkins Rodríguez (nacido en 1955) ocupó importantes puestos dentro del Banco Nacional, en donde se desempeñó como vicepresidente hasta el 2009, cuando ejerció la presidencia por unos meses, la cual abandonó en febrero del 2010.

La familia Jenkins también se destacó como uno de los principales grupos donantes a la campaña de Arias para las elecciones del 2006, y junto con los otros ingenios guanacastecos apoyaron el Tratado de Libre Comercio. ${ }^{5}$ En esta oportunidad, los donativos se encausaron por la vía de varias de sus empresas, pues aparte del ingenio, también emplearon la Corporación Jeromo de San José S.A., la cual estaba dedicada al comercio, la industria, ganadería y turismo, entre otras actividades de lucro. La compañía fue creada en 1993 y en ella participaban cuatro de los Jenkins: Álvaro padre (presidente), José Álvaro (vicepresidente), Esther (tesorera) y Evelyn Matilde (agente de residente), también hija de Jenkins Morales. ${ }^{6}$ Gracias al apoyo de estos y muchos empresarios más, los Arias Sánchez llegaron al poder, pero su verdadero bastión y sustento fue la familia Sánchez, estirpe que manejaba dos azucareras de Guanacaste, y que de inmediato se analizará.

\section{La gran familia Taboga: poder corporativo y político}

De los grandes ingenios de la zona Guanacaste-Puntarenas, el que mayor incidencia política ha presentado es el Ingenio Taboga. Detrás de esta agroindustria se halla el poder de una de las familias de élite más importantes de toda Costa Rica y de la región, los Sánchez de San Francisco de Heredia, descendientes del connotado cafetalero Julio Sánchez Lépiz. Este empresario poseía múltiples terrenos, beneficios y casas, tanto en Heredia como en Cañas, donde se encuentra la azucarera. Amasó su fortuna gracias a las herencias que recibió, pues él y su padre, Juan de la Rosa Sánchez, fueron arrieros de café, pero principalmente debían su capital a su agresiva aplicación de un modelo afín al capitalismo liberal característico de la época, el cual se 
traduce en la obtención de grandes réditos por sus fincas y beneficios de café ubicados en el cantón central de Heredia. Tras su fallecimiento, en 1934, su cuantiosa fortuna fue dividida entre todos sus hijos e hijas, frutos de su segundo matrimonio con la Sra. Emilia Cortés (“El agricultor: Julio Sánchez Lépiz" 1965: 54). En honor a ella, se conformó en los años cuarentas (o un poco antes) la Sociedad Ganadera La Emilia, como entidad encargada de administrar los valiosos recursos ganaderos de la familia (Archivo Nacional de Costa Rica, 1949).

Los Sánchez, por su parte, supieron mantener el legado de su padre y, a partir de 1940, operaron como un consorcio de empresas familiares, con inversiones en café, ganado y posteriormente en caña de azúcar, mientras que en el presente, la diversificación ha sido aún mayor y sus intereses, además de la agroindustria, se extienden a los bienes raíces y a las entidades financieras, así como otra amplia gama de actividades que más adelante se detallarán.

Tras la fundación del Ingenio en 1958, los hermanos Sánchez Cortés fungieron como miembros de la Junta Directiva y controlaban la empresa ganadera nacional. En el segundo quinquenio de la década de 1960, destacaba la participación del ya citado Álvaro Jenkins Morales, quien además de accionista se convirtió en gerente del Ingenio. Esta familia ha integrado un masivo consorcio de empresas. Entre las principales que se han podido rastrear en el Registro Nacional, ${ }^{7}$ están las siguientes, incluyendo sus propósitos y algunos miembros:

- Central Azucarera El Palmar (1958): Liderada por la familia Dobles Sánchez, surgida de la unión entre Trina Sánchez Cortés y el escritor herediano Luis Dobles Segreda (quien fuese vocal) y por consiguiente, nietos de Lépiz. Otra familia muy vinculada a esta cañera, es la cubana encabezada por Mario Miranda, el cual hasta el presente se encuentra como miembro activo -gerente- de esta.

- Julio Sánchez y Hermanos, Sociedad Ganadera La Emilia (1966): Dedicada a la ganadería, el agro y el comercio. Entre sus principales accionistas se encuentran los Sánchez Cortés e incluso Oscar Arias Sánchez como secretario.

- Cafetalera San Francisco Ltda. (1967): Explotación de fincas cafetaleras; constituida por Lillyam Sánchez Cortés, Juan Rafael Arias Trejos y sus hijos Oscar, Cecilia y Rodrigo Arias Sánchez. Tanto Juan Rafael, como Lillyam aportaron múltiples cafetales a la empresa, fusionando el poder cafetalero de dos familias heredianas de mucha influencia.

- $\quad$ Sánchez Gómez S. A. (1968): Agro en general. Liderada por los Sánchez Cortés y la rama Sánchez Gómez; especialmente Julio Agustín Sánchez Gómez, quien fue otro de los hijos de Lépiz y doña Emilia; su hijo Fernando, es el padre del que sería diputado por Heredia, Fernando Sánchez Campos (2006-2010).

- Central Azucarera de Taboga S.A. (1972): Operación de un ingenio, compra, siembra y procesamiento de caña, elaboración y mercadeo de azúcar, mieles y 
otros productos derivados de la caña de azúcar. Es notorio que esta empresa reúne a varios vástagos del matrimonio Sánchez-Cortés, y también la rama Sánchez Gómez, los Arias Sánchez y a Jenkins Morales, quien luego se convertiría en propietario del Ingenio El Viejo. Esta definitivamente es una de las empresas en las que participan muchas ramificaciones de la enorme familia Sánchez.

- Ingenio Taboga S.A. (1974): Operación de un ingenio, compra, siembra y procesamiento de caña, elaboración y mercadeo de azúcar, mieles y otros productos derivados de la caña de azúcar. Esta entidad también incluía a Jenkins Morales, así como a Alfonso Robelo Callejas, Rodrigo Arias Sánchez, Fernando Sánchez Gómez, Carlos Borgonovo Pohl, Mario Hoffmaister Torres, José Lara Tomas, Julio Sánchez Cortés, Francisco Llobet Rodríguez, entre otros. Aparte de los nombres ya conocidos, los Llobet de Alajuela, propietarios de tiendas del lugar, han figurado como miembros de entidades financieras (Mutual Alajuela) y activos miembros de la Cámara de Comercio. Cabe mencionar, que Callejas fue un importante político y empresario nicaragüense, opuesto primero a Somoza y luego al Frente Sandinista, y sus roces con ambas fracciones lo llevaron a exiliarse en Costa Rica.

- Ganadera La Emilia (reformada en 1982 como Sociedad Anónima): Ganadería y afines. Conformada por los Sánchez Gómez, los Arias Sánchez y los Sánchez Benavides.

- Cañera La Emilia S.A. (1983): Toda clase de actividades agrícolas, ganaderas y comerciales, especialmente el cultivo de caña de azúcar y otros. Dirigida por los Sánchez Marín, los Sánchez Gómez, los Arias Sánchez, los Sánchez Benavides, entre otros.

- Destilería Taboga S.A. (1987): Producción de alcohol etílico, así como subproductos derivados. Sus directivos fueron las familias Pérez Cordón, Siemon Arbenz, Pérez Siemon y Arbenz Guzmán. Es sumamente llamativo, que ningún Sánchez sea partícipe directo en esta empresa, aunque es claro que mantenían el control sobre el ingenio. ${ }^{8}$

Estas han sido empresas dirigidas y fundadas por asociaciones filiales de los Sánchez, con miembros de otros grupos influyentes heredianos o de otras partes del país, y demuestran que tres de los cuatro grandes ingenios costarricenses están en manos de las familias Sánchez y Jenkins, las cuales de forma indirecta ayudaron a crear CATSA. Este conglomerado empresarial le ha permitido al grupo Taboga controlar casi todos los aspectos relacionados con la caña, manejar las tierras donde se cultiva la materia prima, el ingenio; influir en la destilería y, de seguro, mantener fuertes contactos con empresas comercializadoras de maquinaria, fertilizantes y otros insumos agrícolas. Igualmente, es conocido que los Sánchez también tienen nexos con otras firmas surgidas en las últimas tres décadas como el Grupo SAMA y el Adral S.A., ambas dedicadas al comercio y las finanzas en general. 
Cabe agregar que Cecilia Arias Sánchez y SAMA Valores S.A. aparecen registradas como accionistas del Grupo Nación, lo que consolida su influencia en los medios de comunicación más prestigiosos del país ("En cumplimiento de lo que dispone la Ley No. 6220 del 20 de abril de 1978, publicada en el alcance No. 78 de la Gaceta No. 89, La Nación, S.A., da a conocer la lista completa de las personas físicas y de los accionistas de la personas jurídicas dueñas de acciones de esta empresa". 2010). Analizada en su conjunto, esta familia herediana cumple el rol de una élite económica "no gobernante", pero adquiere un rol "activo" cuando requiere promover sus intereses en la política nacional. De la misma forma, sus raíces fueron el café y el ganado durante la primera mitad del siglo XX, luego incursionaron con fuerza en la caña de azúcar, y en el presente concentran sus esfuerzos en diversificar sus empresas, incluyendo centros comerciales y residenciales en la provincia de Heredia.

Dado su gran poder material, los Sánchez paulatinamente comenzaron a participar en el campo político. Para ello uno de los pasos fundamentales que dieron fue el matrimonio de la señora Lillyam Sánchez Cortés con el abogado herediano Juan Rafael Arias Trejos. Lillyam fue hija de Sánchez Lépiz y Emilia Cortés, y Arias aportaba al matrimonio no solo cafetales (como lo hizo con la Cafetalera San Francisco), sino que brindó una preciada experiencia política. Su padre fue Juan Rafael Arias Bonilla, con una figuración pública incuestionable, al haber sido legislador, secretario de Estado del Gobierno de Alfredo González Flores, presidente del Congreso y miembro de la Asamblea Constituyente de 1949. Además, Arias Bonilla tuvo una carrera asociada más que todo con los partidos conservadores de la primera mitad del siglo XX y, sumado a sus negocios en el café, técnicamente fue un miembro de la oligarquía cafetalera. Con el matrimonio de Juan Rafael y Lillyam, los Sánchez comenzaron a escalar posiciones dentro de la política nacional, pero aún no era claro con qué partido militarían.

Sin embargo, los hijos varones del matrimonio pronto demostraron ser una mejor opción para irrumpir en la arena política, pues su legado por vena paternal de antemano les auguraba un futuro promisorio, en especial al primogénito: Óscar Arias Sánchez, nacido en 1940. A la joven edad de 20 años, ya se había integrado a las filas liberacionistas, afiliación que no fue fortuita, pues su padre Juan Rafael ya ocupaba puestos importantes en la misma agrupación, fue presidente del Banco Central y luego candidato a la vicepresidencia de la República durante la fallida campaña de Luis Alberto Monge en 1978 (Municipalidad de Heredia, 2010). Óscar también se unió a los negocios familiares con el puesto de secretario de La Emilia a finales de los sesenta, pero pronto se demostró que las cualidades empresariales más bien recaían en su hermano Rodrigo, quien, nacido en 1946, mantuvo una ambigua posición política en su juventud, pues originalmente apoyó al gobierno opositor del PLN, encabezado por José Joaquín Trejos (1966-1970).

Tras sus estudios como economista, politólogo, filósofo, y paralelo a la publicación de algunas de sus obras más importantes, Óscar Arias fue designado en 1970 como 
vicepresidente del Banco Central. Dos años más tarde, el mandatario José Figueres Ferrer lo nombró ministro de Panificación Nacional y Política Económica, cargo que continuó durante el gobierno de Daniel Oduber Quirós, hasta abandonar el puesto en 1975, cuando ocupó la Secretaría Internacional del PLN. En 1978, Óscar fue nombrado diputado, un año después conquistó la Secretaría de su partido y renunció al Congreso en 1981 (para apoyar la campaña de Luis Alberto Monge). Tras el fin de estos servicios, Arias comenzó a perseguir la silla presidencial, pero para ello tendría que sortear otros retos futuros. De momento, su hermano Rodrigo tomó el cargo de presidente de Taboga, posición que mantendría hasta el 2006, mientras figuraba paralelamente como presidente de la Municipalidad de Heredia entre 1975 y 1976.

Para la década de los ochenta, el objetivo de los hermanos era que Óscar alcanzara, primero la candidatura, y luego la Presidencia de la República. Los obstáculos preliminares fueron las figuras de Figueres y Oduber, quienes pretendían llegar una vez más al poder, pero dado que la reelección ya había sido sancionada, sus aspiraciones se vieron frustradas. Por esta razón, depositaron su confianza en Carlos Manuel Castillo Morales, importante intelectual liberacionista, quien además de dirigir el Banco Central, había sido vicepresidente en el gobierno de Oduber.

Sin embargo, Castillo no pudo frenar el apogeo del arismo y los viejos padres del PLN no atinaron más que a brindar su apoyo a la candidatura de Óscar Arias, quien en las elecciones de 1986 derrotó a Rafael Ángel Calderón Fournier. La candidatura de Arias no estuvo exenta de polémica y conflictos internos, pues algunos miembros del partido advirtieron que los medios de comunicación y los grandes potentados de la "oligarquía" pretendían imponer a Arias como candidato, mientras la mayor parte del partido se oponía y solo unos pocos lo seguían incondicionalmente (Brenes, 1983). Por otra parte, Rodrigo Arias fue electo como diputado, aunque en la práctica más bien se desempeñó como ministro de la Presidencia a pedido de su hermano. Durante esta administración, Óscar apoyó resueltamente la cooperativización de CATSA y se fundó la Destilería Taboga S.A.; durante su mandato también se daría un gran empuje al desarrollo de un plan agrícola que benefició la expansión de la caña en Guanacaste (SEPSA, 1987).

Casi quince años después de esta primera administración, José Miguel Corrales, adversario de Arias, precisó que este simplemente utilizó al partido como su gran catapulta política:

Don Oscar no gobernó con Liberación. Oscar nunca fue liberacionista. Es un hombre talentoso y preparado, y vio que era el partido más organizado o menos desorganizado. Por eso es que lo toma como una herramienta para llegar al poder. Sin embargo, su pensamiento nunca ha sido liberacionista. Oscar es el primer hijo de esa vieja oligarquía [la cafetalera] que llega a la Presidencia (Rodríguez, 2002: 6). 
El anterior es un comentario que parece fiel a la realidad, pues claramente esta nueva facción perseguía defender no solo los intereses individuales o familiares, sino también los que incumbían a ciertos círculos de la industria cañera nacional y a otros grupos empresariales a nivel centroamericano. Por esto, es menester referirse al momento crucial de la primera administración Arias, cuando recibió el Premio Nobel de la Paz en 1987, tras mostrar todo su empeño en lograr la armonía en Centroamérica.

Aunque su obra se considera altruista, cabe recordar que el comercio en la región estaba fuertemente afectado y las guerrillas pululaban en las zonas rurales, incluyendo las de Guatemala y, en especial, las de Nicaragua. En el caso costarricense, a lo largo de la década de 1980 se temía por las recurrentes avanzadas y escaramuzas tanto de los sandinistas como de los contrarrevolucionarios somocistas (o "contras"), que operaban en las cercanías de la frontera norte o, incluso, ingresaban a territorio nacional. Ya desde 1979 se alertaba que los sandinistas tenían libre movilización en Guanacaste, sobre todo en Liberia y Peñas Blancas, y que ello constituía una clara amenaza contra la soberanía nacional (García, 1979).

Esto podría llevar a suponer que a los empresarios les preocupaba, por un lado, que la guerra paralizara la producción y, por otro, en el caso específico de los agroindustriales, el estancamiento de la economía guatemalteca y de varios países del área. Especialmente demostrativo resultó el caso chapín, que tras los acuerdos de paz y tantos años de inmovilidad, pasaría a convertirse en el principal productor de azúcar de la región.

En Costa Rica, muchas haciendas del norte de Guanacaste estaban siendo empleadas como bases militares clandestinas por los distintos bandos conflagrados en Nicaragua, por lo que amenazaban directamente los intereses de los grandes empresarios de la zona, los cuales estaban asociados con la política nacional. El problema iba más allá de una simple suposición, pues Arias Sánchez debía estar presionado por grupos muy influyentes y cercanos a él. Los dos casos más precisos eran el de Carlos Borgonovo Pohl y Alfonso Robelo Callejas, ambos partícipes de la Junta Directiva del Ingenio Taboga; el último de ellos, presidente de la empresa durante el gobierno de Arias. ${ }^{9}$

Borgonovo es hasta la fecha un empresario y cafetalero salvadoreño, cuyo hermano Mauricio había sido ministro en dicho país, pero su desenlace resultó trágico, pues fue secuestrado y asesinado por el Frente Farabundo Martí en mayo de 1977 (Cárdenas, 2007). Por su parte, Robelo también había padecido los horrores de la guerra civil en su patria Nicaragua. En 1978, como opositor de la dictadura de Anastasio Somoza Debayle, fundó el Movimiento Democrático Nicaragüense (MDN) junto con otros empresarios. Su posición política lo llevó a buscar refugio en Costa Rica y con la llegada al poder del Frente Sandinista de Liberación Nacional (FSLN) en 1979, su situación no mejoró (Bethell, 2001).

Con la radicalización del nuevo régimen hacia una ideología de izquierda con tintes prosoviéticos, las relaciones con el sector empresarial privado se volvieron 
sumamente tensas, lo cual impidió que Robelo pudiera retornar a su país, optando por mantenerse al mando de Taboga y de otros negocios que tenía en suelo costarricense. Como si fuera poco, un nuevo traspié surgió en 1983, cuando el gobierno estadounidense, liderado por Ronald Reagan, suprimió la cuota azucarera de Nicaragua. Esto caldeó los ánimos de un descontento grupo de inversionistas que pronto se uniría a las voces en busca de una solución inmediata a las disputas bélicas.

Visto en su conjunto, para los empresarios centroamericanos, la guerra se había convertido en un pésimo negocio que equivalía a un estancamiento económico, a sufrir pérdidas monetarias, al asesinato de familiares, al exilio, entre otras desgracias. Buscar una salida a la crisis era imperioso, razón por la cual no es difícil suponer que ejercieran presión para que gobiernos como el costarricense utilizaran todos los recursos a su alcance para promover la pacificación de la zona. En otras palabras, buscar la paz no era únicamente un acto benévolo y avocado a la defensa de los derechos humanos, implícitamente se pretendía traer calma a la región y propiciar la reactivación económica.

Esto no quiere decir que la propuesta de Arias lograra de manera inmediata y eficaz la pacificación del área, pues el tema no era tan sencillo de resolver. Para lograr un cambio, resultaba necesario desarticular el poder armado y la forma más idónea de lograrlo era, en primer lugar, recortar los presupuestos militares en cada país; después, estos oficiales debían reajustar sus funciones y abandonar su papel como gendarmes para dale mayor peso al sector civil. En última instancia, esta reconversión, iniciada en los primeros años de la década de 1990, se tradujo en que las fuerzas militares, principalmente en Honduras y Nicaragua, asumieran un papel de empresas y manejaran desde fincas agropecuarias hasta funerarias, equipos de seguridad, medios de comunicación y agencias de publicidad, entre otras. Ahora el problema lo constituía la competencia del sector privado con los militares, situación sostenida hasta el presente (2010). ${ }^{10}$

De todas formas, Óscar Arias fue galardonado con el Premio Nobel de la Paz, su distinción fue simbólica para el pueblo costarricense, pues reconocía el avocamiento histórico del país a la defensa de la paz, característica encumbrada especialmente cuando Figueres Ferrer abolió el ejército en 1948. Otros sitúan el triunfo en la confluencia de factores, entre los cuales cabe citar el desprestigio que sufrió el gobierno de Reagan tras el escándalo "Irán-contras", la crisis económica que asolaba a Nicaragua, el agotamiento militar de la "contra" y la derrota que sufrían otras guerrillas como la salvadoreña (Pérez, 1997). Además, tras una década de conflagración, no resultaba tan inverosímil que surgiera un auténtico anhelo por la paz entre la población y, en medio de este proceso, resultaba necesario que su gestor fuese un centroamericano, personaje empoderado hasta convertirlo ante los ojos del mundo en un paladín de la no violencia. Sin duda, la riqueza y los contactos exteriores de Arias Sánchez también pudieron ser factores que jugaron a su favor. 
Tras su aclamado galardón, Óscar Arias prosiguió una carrera intelectual en foros internacionales en donde abogaba por la paz y el desarme mundial. Mientras que su hermano, Rodrigo, continuó al mando de Taboga y desempeñó un rol vital dentro del sector azucarero, papel que había ejecutado desde principios de la década de los setenta, al ocupar posiciones claves tales como: director de la Cámara Nacional de Azucareros en 1973, presidente del Ingenio Taboga, S.A. entre 1974 y el 2006; directorpropietario de la Junta Directiva de LAICA entre 1991 y el 2004 y presidente de la Cámara Nacional de Azucareros, desde 1996 y hasta el 2004; entre otros puestos. También fue fundador, fiscal, asesor, director y presidente de la Bolsa Nacional de Valores en los periodos 1977-1985 y 1997-2003. Además, llegó a ser considerado, por personalidades afines al sector cañero, como uno de los principales promotores de la nueva ley cañera aprobada en 1998 (Chaves, 2003).

De esta forma, los hermanos Arias Sánchez se mantuvieron un poco distantes de la política durante la mayor parte del decenio de los noventa, aunque Óscar intentó infructuosamente impulsar la candidatura presidencial de su exesposa, Margarita Penón. A pesar de esta aparente reticencia a inmiscuirse en política, José Miguel Corrales elaboró una explicación de los hechos, al asegurar que Arias solo estaba interesado en figurar como un intelectual de renombre a nivel internacional y cosechar más premios (Rodríguez, 2002). Esta perspectiva, más allá de la crítica puntual, de muchas maneras evidenciaba el verdadero conflicto interno que acaecía en Liberación Nacional; era claro que el arismo había dominado a sus opositores internos.

Así, tras sucesivas derrotas en el plano político, Monge fue incapaz de imponer su hegemonía sobre el partido, mientras que los Arias parecían estar ocupados en sus propios asuntos; sin embargo, una vez acaecida la muerte de Daniel Oduber Quirós, la disputa resultó mucho más evidente, cuando distintos grupos y personajes trataron de tomar el control de la agrupación. En las elecciones venideras, únicamente José María Figueres Olsen logró alcanzar la presidencia bajo el estandarte verdiblanco, tras una dura campaña interna contra el mismo Corrales, quien a su vez disputaría el poder en un entorno copado por las diferentes fracciones disconformes que pululaban en el PLN, como las lideradas por el mismo Monge Álvarez, sus sobrinos Rolando Araya Monge y Antonio Álvarez Desanti. Ninguno logró imponerse y, a finales de los noventa, en su última gran cruzada política, José Miguel Corrales perdió la presidencia ante Miguel Ángel Rodríguez Echeverría, del Partido Unidad Social Cristiana (PUSC).

Durante su campaña no le prestó demasiada atención a los consejos que, en materia económica, le ofrecieron los hermanos Arias y el connotado economista Eduardo Lizano (aunque a Rodrigo Arias se le consideró como un eventual vicepresidente), lo que fue tal vez, un síntoma de las desavenencias existentes en la agrupación (Rossi, 2002). De todos modos, era claro que la familia Sánchez no se encontraba tan alejada de la política como algunos presuponían, más bien vigilaba atenta los conflictos internos y esperaba el momento o los mecanismos idóneos para retornar al poder. 
En el 2002, Liberación nuevamente encaró la derrota cuando Araya Monge (sobrino de Luis Alberto Monge) y fiel seguidor de la labor de Daniel Oduber, fue superado en las urnas electorales por Abel Pacheco de la Espriella, un popular y populista médico psiquiatra que había peleado en la invasión calderonista de 1955. Sin embargo, el debilitamiento del PLN no era la única situación que mostraba la arena política. Pacheco y Araya fueron forzados a una segunda vuelta electoral (algo inédito en la historia reciente del país), ya que no alcanzaron los votos necesarios debido a la inesperada competencia que significó el joven Partido Acción Ciudadana (PAC), liderado por Ottón Solís Fallas, ministro políticamente exiliado por Arias a finales de los ochenta y posterior disidente liberacionista.

El ascenso de Solís y del PAC no fue casual, pues apenas unos pocos años antes muchos miembros de la nueva tendencia se encontraban entre las filas verdiblancas, incluso Solís había sido diputado durante el gobierno de Figueres Olsen (1994-1998); pero una buena proporción de ellos pronto acusaron el hecho de que el partido cada vez tendía más hacia el neoliberalismo y abandonaba el credo socialdemócrata suscrito por Figueres Ferrer y Oduber Quirós.

El mejor ejemplo de las acciones señaladas como nocivas por los más disconformes fue el Pacto Figueres-Calderón, el cual supuso una nueva oleada de reformas neoliberales tendientes a disminuir el aparato estatal, impulsar la aprobación del Programa de Ajuste Estructural III y, más tarde, durante la administración de Rodríguez Echeverría, apoyar el proyecto denominado popularmente como "Combo ICE", el cual pretendía la apertura comercial en telecomunicaciones, dentro de un proyecto auspiciado tanto por el PUSC como por el PLN. Tras no pocos esfuerzos y de haber afrontado una serie de protestas espontáneas y una masiva movilización ciudadana, el "Combo" fue derrotado. A raíz del movimiento, para las siguientes elecciones cobró fuerza la figura de Solís y su partido, que se había presentado como la reivindicadora de los míticos logros del calderonismo y del liberacionismo de viejo cuño.

Aunque una vez efectuadas las elecciones nacionales Pacheco de la Espriella asumió el poder, no gobernaría con facilidad. Antes de ser electo tuvo fuertes roces con Calderón Fournier (fundador del partido) y con el propio vicepresidente de su mandato, Luis Fishmann, a quien terminó por desterrar políticamente. Entre el 2003 y el 2005 negoció y firmó el proyecto del Tratado de Libre Comercio entre la República Dominicana, Centroamérica y los Estados Unidos (CAFTA, por sus siglas en inglés), el cual chocó con una fuerte oposición que condujo a la polarización de la población, dividida entre sus defensores y acérrimos detractores. Eso ocurría en el escenario principal, tras bambalinas otras eran las discusiones y las decisiones que se tomaban.

En las siguientes elecciones, programadas para el 2006, era casi un hecho que el candidato designado por el liberacionismo sería Antonio Álvarez Desanti, o al menos eso aseguraban los medios, mientras que su rival directo era Solís, a quien los analistas avizoraban como eventual ganador. Siendo así, Álvarez no era considerado como la 
pieza idónea para restablecer la fortaleza del PLN, más bien, se temía que acarreara una tercera derrota consecutiva. Sin embargo, la prevención ya se había tomado, a partir de una consulta planteada por la tendencia arista y el subsecuente voto emitido por la Sala Constitucional, que dejaba sin efecto cualquier impedimento para la reelección presidencial.

La batalla personal de Arias para reconquistar la presidencia había comenzado mucho antes, paralela a las derrotas liberacionistas, pues desde 1999 había intentado la aprobación de la reelección sin éxito apreciable, ya que la Asamblea Legislativa se negaba a tocar el tema. Mientras Arias afirmaba convencido que:

La gente me ha dicho 'usted tiene el liderazgo para resolver los problemas que Costa Rica enfrenta'. Yo no sé si eso cierto, pero ellos lo creen y yo también lo creo. Los costarricenses siempre encontrarán en mi transparencia politica, que si prometo algo en campaña cumplo mi palabra en el Gobierno. Que existe coherencia entre mis palabras y la acción, entre lo que predico y lo que hago (Herrera, 1999: s. p.).

De previo, La Nación venía publicando encuestas en las que Arias figuraba como el político más popular de Costa Rica, con mejor preparación y con la capacidad de tomar las decisiones que el país exigía. Sin duda, el citado diario estaba preparando la campaña de Arias y lo mostraba de una forma casi mesiánica ante la ciudadanía (Matute, 1998).

Acto seguido, el mismo rotativo insistió en una campaña mediática, en la cual, a través de más encuestas, aseguraba que la mayor parte de la población estaba de acuerdo con la reelección, pero prefería la aprobación por la vía legislativa, y así presionar de manera implícita para que el Congreso al menos comenzara a tratar el tema. Sin embargo, la coacción apenas comenzaba, pues Arias ni siquiera contaba con el apoyo unánime dentro de su propio partido para impulsar la iniciativa, situación que lo llevó a utilizar las votaciones distritales del PLN, efectuadas en marzo del 2000, como un mecanismo de consulta popular. En ellas, un 88 por ciento de los participantes (de un total de 106 878) afirmó estar de acuerdo con la reelección, lo que allanaba aún más el camino del aspirante presidencial.

Ante un panorama tan promisorio, Arias decidió mostrar su caso a las autoridades, con la esperanza de que estas le dieran una respuesta favorable y escucharan el supuesto clamor popular. El primer mecanismo empleado para este fin radicó en un recurso de inconstitucionalidad en setiembre de 1999 ante la Sala IV. El trámite fue presentado por los abogados Jorge Méndez y Edgardo Picado, el cual argumentaba que la decisión que entre 1966 y 1969 sancionó la reelección, presentaba ciertos fallos constitucionales y, ante todo, violaba los derechos humanos del ciudadano. Pese a esto la Sala, presidida por Rodolfo Piza, desechó la petición en setiembre del 2000 y con ello la reelección lucía imposible, decisión celebrada por los miembros prominentes del liberacionismo y por casi todos los expresidentes. 
Años después, Guido Sáenz, exministro de Cultura, levantó polémica sobre el tema, al citar en una biografía que un magistrado traicionó a Arias e impidió la reelección en el año 2000. Esta nota la publicó en Piedra azul: atisbos en mi vida, donde afirmaba:

De los siete votantes de la Sala Constitucional, cuatro se pronunciaron en contra, tres a favor. Lo llamé (se refiere a Arias) en cuanto me enteré de la catástrofe. 'Guido, yo estaba ciento por ciento seguro de que me pasaban la reforma. Tenía la promesa de cuatro magistrados. Uno me traicionó (Venegas y Villalobos, 2004: s. p.).

Cuando el libro se publicó, las críticas no se hicieron esperar, pero Sáenz se disculpó ante Arias y compareció ante la Asamblea Legislativa al argumentar que la cita solo fue una mera figura literaria, error un tanto inocente, pero que bien se lo podía permitir un literato en un escrito de esa índole.

Ciertamente, la decisión de la Sala IV enfureció a muchos sectores; por su parte, La Nación dejó ver que los precandidatos liberacionistas (Antonio Álvarez, José Miguel Corrales y Rolando Araya) habían presionado para que los magistrados rechazaran la reelección. Detrás de la denuncia, era evidente que los azucareros trataban infructuosamente de controlar su frustración ante este primer revés. Sin embargo, el verdadero empuje a las intenciones de los Arias no provenía de meras encuestas, más bien se sustentaba en el aparente apoyo de las demás fuerzas políticas del país, especialmente de Figueres Olsen, Calderón Fournier y Rodríguez Echeverría, quienes comenzaron a reunirse con los hermanos Arias para llegar a un consenso en torno a la reelección. Los pormenores de estas citas fueron narrados por el mismo Óscar Arias:

La primera vez que se me envió un mensaje fue cuando mi hermano Rodrigo, junto a (el empresario) don Rodolfo Jiménez, visitaron al presidente de la República Miguel Ángel Rodríguez en la Casa Presidencial para hablar de otro tema y don Rodolfo introdujo el de la reelección.

Don Miguel Ángel le dijo a mi hermano: 'nada me gustaría más que poderle pasar la banda presidencial a Oscar y nada me convence, después de un año de gobierno y las dificultades que he tenido para aprobar legislación importante, que luchar por la reelección presidencial.

Eso llevó a don Rodolfo Jiménez a invitarnos a los expresidentes José María Figueres, a Rafael Ángel Calderón y a mí a una reunión con mi hermano y con don Rolando Laclé, y hemos tenido muchas reuniones. Hemos desayunado muchas veces en la casa de don Rolando Laclé, donde don Rodolfo Jiménez, donde don Miguel Ángel, para hablar de este tema ("Arias: me embarcaron", 2000: s. p.). 
En realidad, en estas primeras reuniones, la figura que más destacaba era la de Rodolfo Jiménez Borbón, connotado empresario hijo de Manuel Jiménez de la Guardia y considerado uno de los hombres más poderosos de la Costa Rica contemporánea, principalmente por su importante emporio económico y mediático. Es imperioso un breve paréntesis con el objetivo de detallar la influencia y poder de este distinguido personaje. La familia Jiménez ya se había destacado en la primera mitad del siglo XX a través de Manuel Francisco Jiménez Ortiz, importante abogado que fungió como canciller de la República, ministro de Ricardo Jiménez (1932-1936) y diputado constitucional en 1949. La fortuna sonrió con creces a esta familia y a finales de la década de 1940, adquirió la Hacienda Juan Viñas en Cartago, una de las principales productoras de azúcar (con la marca del mismo nombre) y luego, de la mano de Jiménez de la Guardia, compraron en el mismo periodo, el diario La Nación. Actualmente Jiménez Borbón mantiene el legado familiar y figura como uno de los principales accionistas y presidente de la Florida Ice and Farm Company (FIFCO, la “Cervecería Costa Rica”), la cual maneja múltiples marcas de bebidas en toda la región centroamericana (Florida Ice and Farm Company, s. f.).

Las reuniones entre los principales dirigentes políticos del país y Jiménez acaecieron entre el año 2000 y 2001, aunque muchas más pudieron haberse celebrado antes y después, pero siempre en un entorno marcadamente privado. Una de estas citas tuvo lugar en la casa del citado empresario y con la presencia de los hermanos Arias Sánchez, Figueres Olsen, Calderón Fournier y Rodríguez Echeverría, en donde el tema de fondo fue precisamente la reelección. José Miguel Corrales en aquellos años era precandidato y públicamente mantuvo profundas diferencias con las ambiciones de Óscar Arias. En vísperas del arranque de la campaña electoral en el 2001, brindó su perspectiva acerca de estos encuentros, así como del supuesto origen de las mismas. Incluso, sus palabras siguen prestándose al debate:

Don Rodrigo Arias visitó la Casa Presidencial para pedirle a don Miguel Ángel que el azúcar no figurase en el Tratado de Libre Comercio con Chile. Y, de esta conversación, surgió la oportunidad de hacer una exclusiva reunión en la residencia de don Rodolfo Jiménez Borbón, cuyos intereses, también azucareros, se centralizan en Juan Viñas, como es de dominio público. La cita se amplió a Miguel Ángel Rodríguez, Rafael Ángel Calderón, José María Figueres, Óscar Arias y su hermano, amén del anfitrión, don Rodolfo. Y tras el asunto del azúcar, que no a todos involucra, se profundizó en la política. Para ellos, ningún precandidato es fiable para sus intereses. Aprovechando los indices de los sondeos, el hombre de confianza, de garantía, era Óscar Arias. Estuvieron de acuerdo. Y tan conformes que se produjo, ipso facto, el maná costoso de una campaña millonaria ("Reelección empezó con el azúcar...", 2001: 3).

Corrales luego aseveró que el proyecto fracasó por el temor de Calderón a que el PUSC fuera derrotado por la victoria aplastante de Arias. Sin embargo, este razonamiento 
resulta un tanto ligero y menospreciaba los alcances que la iniciativa pretendía. El delicado consenso surgido de estos cruces de opinión estableció que el plan de acción era simple: reactivar la reelección presidencial y que los viejos cabecillas volvieran a tomar las riendas del descarriado país.

Dado que la Sala IV no lo permitía, entonces la querella sería solucionada en el Congreso; para ello, la totalidad de los diputados del PLN, más los que hicieran falta del PUSC, reformarían la Constitución (acción que exigía 38 votos de 57). No obstante, dado que el PLN estaba dividido y primaba la facción de Corrales, se optó para que todos los legisladores de la Unidad, junto con los liberacionistas fieles llevasen a cabo la reforma. Ese fue el acuerdo final. Sin embargo, en último momento, Calderón y Rodríguez abandonaron el plan y dieron marcha atrás, por lo que la reelección no fue discutida.

De nuevo las intenciones de los Arias se vieron truncadas, no solo por la decisión de Calderón y Rodríguez, sino porque también influyeron los precandidatos liberacionistas para las elecciones de 2002: Corrales, Desanti y el eventual ganador, Araya; quienes pactaron con el PUSC. A cambio del apoyo de los diputados del PLN en la agilización del proceso de aprobación del "Combo ICE”, Miguel Ángel Rodríguez no llevaría a discusión parlamentaria el proyecto de la reelección, con lo cual todos mostraban muy claramente su animadversión a las intenciones del proponente. Por supuesto, los precandidatos desmintieron las acusaciones de "traición" formuladas por Arias y más bien recalcaron que él era quien hacía pactos a espaldas de todos, tanto con Calderón como con Jiménez (Vargas, 2000).

Arias probablemente perseguía llegar a la presidencia en 2002, pues sus ambiciones se remontaban al año 1998. Pero, ¿qué estaba ocurriendo, a qué se debía la prisa? En ese momento los grupos económicos más poderosos de Costa Rica, entre los que se encontraban las familias Jiménez y Sánchez, estaban a la expectativa del CAFTA, el cual se negociaría después del 2002; ambas representaban a su vez a dos poderosos grupos cañeros, que a pesar de algunas diferencias previas, en ese nuevo contexto, presentaban intereses comunes.

También eran conscientes de que el "Combo ICE" había sido vapuleado y que aprobar tanto el TLC como otros proyectos de corte neoliberal, no iba a ser sencillo, especialmente cuando las lealtades de los partidos tradicionales estaban divididas, pues en la última década, los Arias se habían distanciado más y más del PLN. En este punto la confrontación era manifiesta y las discrepancias con la nueva cúpula del partido se iban acrecentando, principalmente con Araya, Corrales y Álvarez. Ellos y muchos otros políticos del PLN como Luis Alberto Monge, se mostraban totalmente contrarios a una eventual reelección, pues estaban muy conscientes de la inmensa popularidad de Arias. La solución momentánea, mientras se lograba la reelección, era conseguir la lealtad de un candidato cuya victoria fuera segura, por lo cual el más idóneo resultó ser Abel Pacheco de la Espriella. 
Anteriormente se había hecho referencia a este personaje y a sus diferencias con Calderón, pero es indispensable agregar algunos detalles. En el año 2000, Pacheco anunció oficialmente su precandidatura (la cual corrió casi paralela al rechazo de la reelección), pero de inmediato y al igual que Arias, chocó con muchos escollos. Públicamente fue conocida la oposición de los líderes del PUSC -Calderón Fournier y Rodríguez Echeverría-, quienes tenían profundas diferencias con el psiquiatra. En 1998, Pacheco anunció de manera poco c alculada -y sin evidencias- supuestos nexos de Rodríguez con un narcotraficante mexicano; de inmediato, tras el anuncio de sus intenciones presidenciales, Calderón calificó a Pacheco de políticamente inexperto y de inestable a nivel emocional (Ramírez, 2001). Con facilidad se podría argumentar que estos roces eran típicos de la carrera por la presidencia, en especial en tiempos de campaña, pero fue evidente que los diferendos no se zanjaron del todo y estallarían años después, como se precisará más adelante.

De momento, debe hacerse hincapié en la campaña de Pacheco, la cual fue financiada ampliamente por Jiménez Borbón y, una vez que ocupó la presidencia, saltaron dudas acerca de estos dineros. Ante los cuestionamientos, la Asamblea Legislativa convocó a Jiménez para que explicara lo ocurrido, de manera resuelta detalló:

Frente a la realidad públicamente conocida de que el nombre del doctor Pacheco no era bien recibido por algunas estructuras formales del Partido Unidad Social Cristiana, algunos ciudadanos amigos de don Abel decidimos trabajar, fuera del partido, solicitando donaciones para impulsar, primero la precandidatura y luego, la candidatura', leyó Jiménez en su declaración inicial. Jiménez, accionista de La Nación y de la Cervecería Costa Rica, entre otras compañias, detalló sus donaciones personales a la campaña de Pacheco: un cheque personal de $\$ 10$ millones y dos cheques -cada uno por $\$ 5$ millones-girados por dos de sus empresas a favor de Pacheco, así como dos cheques por $\$ 5.000$ para el PUSC. Además de sus aportes personales, Rodolfo Jiménez leyó una lista de donaciones recaudadas por él a favor de Pacheco por cerca de \$149.000, pues en algunos casos no recordó la cifra. Entre los donantes citó a los empresarios André Garnier, Eduardo Uribe y Carlos Montealegre; al Banco Banex y a la compañía Beneficios Volcafé (Segnini, Rivera y Herrera, 2003: s. p.).

En otras palabras, Jiménez no confiaba abiertamente en Calderón y sus aliados, en razón de lo cual respaldó a Pacheco por otras vías, formando en la práctica "otro partido o tendencia" dentro del PUSC. El nuevo mandatario mantuvo su distancia con respecto a Calderón, mientras que las críticas caían como avalancha cuando designó a Rodrigo Arias como asesor, cargo - ad honorem- que mantuvo por seis meses.

Esta asesoría no fue casual y más bien resultó limitada si se comparaba con las intenciones originales, ya que Abel Pacheco, a través de Luis Fishman, le había ofrecido una vicepresidencia a Rodrigo Arias, quien aceptó meditarlo, pero al final no accedió, pues posiblementehubiera desembocado en un gigantesco escándalo. Tras la salida de los hermanos Arias Sánchez, Pacheco aseguró que mantenía relaciones muy cordiales con ambos. 
Tras los anteriores reveses en torno al tema de la reelección, finalmente se dio un cambio de magistrados en la Sala Constitucional, momento oportuno para la presentación de un nuevo recurso, dado que el grueso de los que antes habían votado en contra de la opción para ese momento ya se habían retirado. Fue entonces cuando en abril de 2003 una mayoría dio luz verde a la añorada petitoria. Pasaría poco tiempo para que una nueva controversia se desatara, cuando los expresidentes (tres de los cuatro que estuvieron presentes en las reuniones con Jiménez) fueron acusados de corrupción y otros delitos asociados con abusos en sus funciones públicas. De inmediato se dio una inmisericorde campaña mediática que censuró a los políticos y dio larga cobertura a los arrestos de Calderón Fournier y Rodríguez Echeverría; en tanto, censuraba el exilio en Suiza de Figueres Olsen. Con la salida de Álvarez Desanti y las acusaciones que pesaban sobre los demás exmandatarios, el terreno estaba preparado para la nueva escalada de Arias hacia la silla presidencial. ${ }^{11}$

Acto seguido y casi de forma paralela a estas persecuciones, en el transcurso del año 2004 el CAFTA era negociado y firmado, fase en que los líderes del PUSC estaban siendo sitiados por las autoridades competentes, las cuales tejían complicados casos legales en su contra. Ambos procesos dividieron y amedrentaron a los partidos políticos y, dado que en el PLN y en el PUSC primaban muchos diputados asociados a las líneas de Corrales, Araya, Calderón y Rodríguez; sumado a los desertores que se reportaban en ambos colectivos y al fortalecimiento del PAC, la aprobación del Tratado de Libre Comercio resultó muy difícil.

Era públicamente conocido que muchos diputados estaban descontentos con sus respectivas bancadas, sumaban 11 los independientes; por lo cual, una votación del CAFTA en momentos de tumulto político hubiera sido larga, tediosa e infructífera para los intereses del gremio cañero y sus asociados (Venegas, 2005). Paulatinamente, pero a cada momento con más precisión en los detalles, el Gobierno de Pacheco lucía ante los medios de comunicación como mediocre, dubitativo y sin rumbo; entretanto, la amenazante campaña de Arias arrancaba presentando a su candidato como el nuevo capitán del barco y el único hombre capaz de echar a caminar al país.

En este contexto, muchos disidentes de los partidos mayoritarios terminaron por unirse a los Arias, hartos de la actitud de Pacheco o amedrentados por la desestructuración partidista reinante. Resulta altamente factible, que los Arias, Jiménez y Pacheco estuvieran al tanto de que la aprobación del Tratado era imposible durante el periodo 2002-2006 y, por tanto, se hacía necesario contar con una fuerza de diputados comprometidos con esta tríada. Por lo demás, toda la batería política y recursos económicos de sus correligionarios, del gremio azucarero y de otros grupos empresariales interesados, incluso de orden transnacional, se pusieron a disposición de la campaña del PLN.

A pesar de que muchos competidores fueron retirados de la arena, Arias Sánchez tuvo una reñida batalla con Solís Fallas, pero su experiencia, capacidad y 
popularidad, prevalecieron sobre su oponente directo. Así pues, los hermanos Arias contaron con muchos factores a su favor, una vez alcanzada la presidencia. Llegaron acompañados de una bancada parlamentaria de 25 diputados fieles a su causa, que dieron su total adhesión al CAFTA; además, contaron con el apoyo de otros grupos minoritarios como el Movimiento Libertario (de herencia liberal). Amparada en este bloque, la conquista del Tratado era casi una realidad, la cual fue concretada tras ganar el referéndum del 2007 que le dio el último empujón al proyecto estrella del gobierno de los Arias.

Era evidente que con su triunfo, los cañeros estaban cerca de finiquitar el CAFTA y con ello asegurarse una importante cuota en el mercado estadounidense, pero, ¿qué ganaba personalmente Óscar Arias Sánchez? Podría suponerse que su meta radicaba en cumplir las alianzas establecidas con ciertos grupos de la burguesía, los cuales requerían de una persona con una buena imagen pública. Aún más, con su triunfo, su hermano Rodrigo, altamente capacitado en asuntos políticos y empresariales, pero con menor proyección pública, cumpliría el rol que le asignaron, sin duda su familia y corporaciones afines: la de optimizar sus negocios.

Al ser la popularidad una de las razones que llevaron a los grupos dominantes a impulsar la candidatura de Arias, resulta del todo curioso que fuera uno de los aspectos en los que más terreno perdió durante los siguientes años. Para los grupos opositores, atacar la imagen de los hermanos, era un intento por deslegitimar su gobierno y sacudir sus políticas. Por ello, amplios sectores sociales acusaron a Óscar Arias, y a veces también a su hermano, de ególatra y adicto al aplauso.

Ante estos ataques, la reacción de sus aliados fue el apoyo, con lo que la promoción de su imagen fue abiertamente realizada por medio de cadenas televisivas, biografías y otros mecanismos; sin embargo, las críticas no cejaron y en contra de los Arias se presentaron muchos recursos legales que los acusaban de corrupción y de llevar a efecto medidas políticas indebidas. Cuando autoridades como el TSE y las cortes judiciales desestimaban las acusaciones, los bloques opuestos argumentaban acertadamente que Arias y sus aliados político-económicos (Jiménez y los demás azucareros) controlaban los medios de comunicación y que, con sus vastos recursos, también manejaban las diferentes instancias gubernamentales, entre las que se podía citar a la Sala IV y a la Asamblea Legislativa.

Veinte años atrás, cuando los hermanos derrotaron a Figueres Ferrer y a Oduber Quirós para asegurarse la candidatura y luego a Calderón Fournier para amarrar la silla presidencial, ambos se presentaban como jóvenes ambiciosos. En el 2006, Óscar Arias trató de presentar como sus credenciales máximos el Premio Nobel de la Paz y su labor como conferencista internacional. En la práctica quedó claro que era un empresario con infinidad de inversiones e intereses en distintos negocios. En su declaración jurada de bienes ante la Contraloría, precisó: 
Como parte de su capital, Óscar Arias Sánchez posee el 14,75\% del capital social del Grupo Consolidado SAMA, "compañía dedicada a la intermediación bursátil". Igual declara que tiene el 100\% del capital social de la Corporación ADRAL S.A., dueña de un porcentaje de los activos del Ingenio Taboga (3,22\%), Inversiones La Lillyana S.A. (33,33\%), Montarás del Norte S.A. (33,33\%), Futuros ORAS S.A. (50\%), Tenedora G.S.A (8,11\%) y Corporación Pipasa (6,26\%). De Corporación ADRAL S.A., también es propietario de dos terrenos en La Cruz, Guanacaste... (Pérez, 2005: s. p.).

Mientras los hermanos Arias Sánchez encabezaban el gobierno, otros familiares muy cercanos ocuparon puestos importantes, pero no contaron con los mismos niveles de invulnerabilidad. Entre estos, se destacó Fernando Sánchez Campos (nacido en 1974), quien fungió como diputado por el cantón central de Heredia. El congresista era hijo de Fernando Sánchez Gómez y nieto de Julio Sánchez Cortés, otro de los vástagos de Julio Sánchez Lépiz. Algunos rumores populares apuntaban a que Sánchez Campos y el resto de su familia eran poseedores de más de tres millones de acciones del Ingenio Taboga a través de la empresa Cafetalera San Agustín S.A., lo cual probablemente le dio una posición ventajosa dentro del gobierno de su primo.

Fernando luego protagonizó un escándalo al lado del vicepresidente Kevin Casas Zamora, cuando trascendió públicamente su vínculo con la autoría de un correo electrónico que invitaba a defender el CAFTA con todo tipo de estratagemas. En el escrito se hacía énfasis en que el miedo debía ser la principal forma de promover el Tratado entre la población; por ejemplo, atemorizar con posibilidades como la pérdida de empleos o bajo la amenaza de que ciertos países con regímenes izquierdistas intervendrían en la política nacional (como Cuba y Venezuela). En suma, urgía al gobierno emplear todos sus recursos en extensas campañas mediáticas, publicaciones y visitas de los altos representantes del Poder Ejecutivo a empresas, con el fin de promover el acuerdo. ${ }^{12}$ Esto afectó sensiblemente la carrera de ambos políticos, en especial la de Casas, quien renunció a su puesto y con ello se esfumaron sus aspiraciones políticas futuras. Por el contrario, Fernando Sánchez se mantuvo como diputado a pesar de las presiones de distintas organizaciones. Al final el TSE y el Congreso no prestaron mayor atención a las denuncias en su contra, pues de todas formas contaba con el apoyo de sus primos en Casa Presidencial y de la familia Sánchez en general. A partir del 2010, fue designado como embajador ante el Vaticano.

Otro familiar que formó parte del Gobierno, fue el exministro de ambiente, Roberto Dobles Mora, hijo de Manuel Dobles Sánchez y nieto del ilustre escritor Luis Dobles Segreda (esposo de Trina Sánchez Cortés). La ignominia también sacudió a Dobles, pues se reveló que había firmado una concesión minera a la empresa Agricultura Mecanizada Chapernal, cuyo vicepresidente era su tío Jorge Dobles Sánchez, quien a su vez era primo de los hermanos Arias. Adicionalmente, la citada compañía figuraba como accionista del ingenio El Palmar, el cuarto más 
grande del país; así que, tras estas denuncias, tomó la decisión de renunciar a su cargo. En tal oportunidad, el mismo Óscar Arias precisó los nexos entre él y los Dobles. Al respecto la Prensa Libre publicó:

Se le preguntó a Arias si conocía de ese parentesco entre los Dobles y El Palmar y sin entrar en más detalles, contestó: 'si toda la familia Dobles son los dueños de El Palmar, quién duda que la familia Arias Sánchez y todos los Sánchez de Heredia y un montón de gente más tienen acciones en el ingenio Taboga, no hay nadie que dude. Ahora, si dio una concesión para que la finca se utilice para extraer la arena y la piedra para mejorar caminos, que viene desde el año 2001 y que lamentablemente le tocó a este Gobierno y a él firmar la concesión, fueron cosas del destino' (Alpízar, 2009: s. p.).

Arias fue muy claro, los Sánchez eran la familia más poderosa dentro del gremio cañero, puesto que controlaban a dos de los ingenios más grandes del país y como su primo Fernando mencionó: su familia era pionera de la producción del azúcar en Guanacaste, de eso no cabe duda. Aunque los ataques contra los hermanos nunca cesaron, ambos se mantuvieron firmes en sus respectivos puestos. Rodrigo intentaría alcanzar la presidencia en 2014, pero con resultados infructuosos.

\section{Conclusiones}

Es importante destacar que los cuatro ingenios del Pacífico seco pertenecen o han sido fundados por un conglomerado empresarial encabezado por dos familias, los Sánchez y los Jenkins. Del mismo modo, ambos se han nutrido de la colaboración y transferencia de conocimientos de la industria azucarera cubana, por medio de la estirpe Miranda en El Palmar, o los Rovira en El Viejo. Estas relaciones van más allá, pues otros empresarios centroamericanos también han sido partícipes del auge azucarero y en este caso los ejemplos sobran: Robelo (nicaragüense) y Borgonovo (salvadoreño) en Taboga y por supuesto, el más controvertido y el que más crónicas ha suscitado, es el de Somoza y sus amistades con El Viejo. Con esto se quiere reafirmar que los nexos políticos y empresariales van más allá de nuestras fronteras y los procesos exógenos como guerras civiles, golpes de Estado o la conformación de élites centroamericanas, tienen un profundo eco dentro del sector cañero costarricense y empresarial en general.

Es evidente que la burguesía se encuentra asociada a grupos transfronterizos, pero no exclusivamente como "socios menores". Cada vez ha cobrado más fuerza el argumento de que las élites son entreguistas y sometidas al capital e intereses foráneos. Esta idea es respetable, pero discrepamos al menos en el caso del sector cañero, considerando que simplifica mucho los fines de las élites, no solo la cañera, sino la empresarial en general. Estas fracciones dominantes no están atadas a una noción clásica de nación o nacionalismo, las fronteras no les importan y, ante todo, priman las posibilidades de ganancias, así como las alianzas establecidas con los cañeros del 
istmo. De ahí que para dichos empresarios sea más valioso el crecimiento del sector que los intereses locales; incluso, se podría agregar que no se trata de "vender" a un determinado país, lo que se busca es usufructuarlo al aumentar las riquezas personales, por eso cabe recordar que es una lucha de élites y algunas tienen que perder (o son forzadas a ello).

\section{Notas}

1 Se retomaron postulados de los intelectuales italianos Pareto, Mosca y por supuesto, Gramsci. En resumen, se consideraron los grupos de poder como entidades que buscan la hegemonía, construyen alianzas, pueden perder su poder o símbolos de éste (como el "prestigio"); así como algunas pueden tomar un rol económico y otra prefieren ostentar funciones políticas. Más importante, lejos de calificarlas como dinastías sempiternas, se trató de analizar cómo se originaron, sus estrategias para ascender y asegurar su poderío; así como los costos [políticos] que esto ha tenido. Algunos de los detalles teóricos fueron retomados de la obra de Irving Zeitlin.

En la actualidad subsisten poco más de una docena de ingenios, pero el predominio lo concentran los cuatro grandes del Pacífico seco. Por otra parte, ya en otro trabajo tratamos de demostrar que el apoyo estatal es de larga data y esencial para el despegue productivo y la rentabilidad de la caña en la zona del río Tempisque (Marchena, 2015).

Aunque hijo natural de Pinto, empleaba los apellidos de su madre, la Sra. Luisa Robles Guzmán (Urbina, 1981: 11A).

Otra referencia - un tanto confusa - apunta a que El Viejo fue alquilado o adquirido por un inversionista del estado de Virginia, mismo que estaba obteniendo terrenos en el distrito de riego y cuyas propiedades incluían: Rancho Horizonte, Rancho Gesling y el ingenio Las Piedras (Edelman, 1987: 104-105). El trasfondo de estas operaciones obedecía a especulaciones por parte de estos inversionistas. Asimismo, cabe destacar que no se localizaron documentos primarios que reafirmen o aporten nuevas luces a estos movimientos y en la nota número 10 del citado artículo de Edelman, él mismo especificó que parte de su información provenía de conversaciones informales: "...una fuente cercana a las operaciones" (Edelman, 1987: 107); lamentablemente, se desconoce esa fuente y de momento, no se pueden agregar más datos.

Junto con Rodrigo Arias, Mario Miranda (El Palmar), Gonzalo Cubero Brealey (CATSA) y el Ingenio Quebrada Azul, constituyeron Arias Presidente S.A. Solo Jenkins donó más de 17 millones de colones (Tribunal Supremo de Elecciones 2005 folios 1.225 y 1.304).

Información extraída de: Registro Nacional de Costa Rica. Personería jurídica, tomo n. 770, folio 128 y asiento 145.

La fecha que se cita al lado de cada empresa, corresponde al año en que aparecieron registradas ante la Sección Mercantil del Registro Nacional, cuando aparentemente se repiten empresas, como el Ingenio y la Central Azucarera de Taboga, pueden ser la misma compañía, con un cambio de nombre o subsidiarias paralelas, como podría ser el caso de las múltiples La Emilia que presentamos.

8 En la bibliografía se incluyó el detalle de todos los tomos y asientos revisados en el Registro Nacional para la elaboración de la síntesis de empresas de la familia Sánchez. 
10 La Fundación Arias para la Paz y el Progreso Humano, fundada por Oscar tras recibir el Premio Nobel, encomendó parcialmente al futuro vicepresidente de la República de éste, Kevin Casas, coordinar una investigación acerca de los militares y sus empresas en Centroamérica, a todas luces era claro que aunque ya habían acabado las guerras civiles y los ingenios volvían a operar a toda máquina, los empresarios de la región ahora tenían que soportar la competencia con los militares, un grupo poderoso, capaz de efectuar golpes de Estado y que cuenta con muchos nexos políticos. El estudio es llamativo y sin duda deja entrever, que esta Fundación de Oscar Arias es un grupo estratégico para los empresarios regionales, su papel deja muchas preguntas pendientes (Brenes y Casas, 1998).

11 Y no titubeó en exigirle a Figueres Olsen que renunciara de inmediato al partido, Arias comenzaba a exigir el poder absoluto dentro del PLN, muchos otros "disidentes" también tendrían que abandonarlo (Urbina, 2004).

Una copia de este documento, derroche maquiavélico de estrategia política y propaganda política se encuentra en: "Memorando Casas-Sánchez", http://alainet.org/active/19600, (Fecha de acceso: 28 de mayo del 2010).

\section{Bibliografía}

Aguilar Arroyo, Yensy. "Una de las pocas haciendas típicas”, Al Día, 26 de julio del 2009. $<$ http://www.aldia.cr/ad_ee/2009/julio/26/nacionales2027994.html>.

Alpízar Corella, Karina. "Arias no se someterá a Comisión de Ética del Poder Ejecutivo". La Prensa Libre, 9 de marzo del 2009. <http://www.prensalibre.co.cr/2009/marzo/09/ nacionales04.php>.

Archivo Nacional de Costa Rica. Ministerio de Hacienda-Tributación Directa \#18554, 1949.

Bethell, Leslie (ed.). Historia de América Latina. 14. América Central desde 1930. Barcelona, España: Crítica y Cambridge University Press, 2001.

Brenes Vega, Juan Luis. "Se acabó el mito de Oscar Arias en el Partido Liberación Nacional". La Nación, 20 de octubre de 1983, 11A.

Brenes, Arnoldo y Casas, Kevin (eds.). Soldados como empresarios. Los negocios de los militares en Centroamérica. San José, Costa Rica: Fundación Arias para la Paz y el Progreso Humano, 1998.

Cabanas, André. “Guatemala: dos países. Revista Pueblos, 2009. <http://www.revistapueblos. org/spip.php?article1532\#nb8>.

Cabrera, Roberto. Tierra y ganadería en Guanacaste. San José, Costa Rica: Editorial Tecnológica, 2007.

Cárdenas López, Hugo Mario. “Otros secuestros de empresarios”. El País, 26 de abril del 2007, A4.

Chaves Solera, Marcos (ed.). Congreso XV de la Asociación de Técnicos Azucareros de Costa Rica. Guanacaste, Costa Rica: Asociación Nacional de Técnicos Azucareros de Costa Rica, 2003.

COVERCO. Diagnóstico de la industria del azúcar. Guatemala: COVERCO, 2004.

Edelman, Marc. "El distrito de riego de Guanacaste (Costa Rica) y la política del agua". Anuario de Estudios Centroamericanos 13, 1987: 95-111. 
Edelman, Marc. “Un Estado dentro de otro: las propiedades de Somoza en el norte de Costa Rica". Revista de Ciencias Sociales 66 (1994): 21-28.

Edelman, Marc. La lógica del latifundio. San José, Costa Rica: Editorial de la Universidad de Costa Rica y Stanford University Press, 1998.

Florida Ice and Farm Company. "Junta Directiva", <http://www.florida.co.cr/info_corp_es/ junta_directiva.php>.

García Castro, Abelardo. "Sandinistas tienen libre movilización en Guanacaste”, La Prensa Libre, 10 de julio de 1979, 11.

Grainger, Sarah. "Exportación azúcar Centroamérica subiría 7.5 pct”. Reuters, 20 de mayo del 2009 <http://lta.reuters.com/article/businessNews/idLTASIE54J24820090520>

Gudiel, Vernick y Álvarez, Lorena. "Los dueños de América Central”. La Gente, 18 de abril del 2006, <http://www.radiolaprimerisima.com/noticias/1517>.

Herrera, Berlioth. “Oscar Arias tras la reelección”. La Nación, 2 de diciembre de 1999, <http:// wvw.nacion.com/ln_ee/1999/diciembre/02/pais1.html>.

"Honduras: artificialmente encarecida por el gobierno y los monopolios". Revistazo, s. f. $<$ http://www.revistazo.com/junio-03/docprincipal.htm>.

Liga Agrícola e Industrial de la Caña de Azúcar. Conexión, 6 enero del 2012.

"Arias: me embarcaron". La Nación, 24 mayo del 2000, <http://wvw.nacion.com/ln_ee/2000/ mayo/24/pais2.html>.

“Duelos sociales. Dr. Don Fernando Pinto E.". La Nación, 3 mayo de 1957, 22.

"El agricultor: Julio Sánchez Lépiz". La Nación, 10 de diciembre de 1965, 54.

"En cumplimiento de lo que dispone la Ley No. 6220 del 20 de abril de 1978, publicada en el alcance No. 78 de la Gaceta No. 89, La Nación, S.A., da a conocer la lista completa de las personas físicas y de los accionistas de la personas jurídicas dueñas de acciones de esta empresa", La Nación, 30 Jun. 2010, 20A - 21A.

Marchena Sanabria, Jorge. "El nacimiento de las corporaciones azucareras en Guanacaste, 1890-1970”. Diálogos: Revista Electrónica de Historia 16, 2 (2015): 83-119.

Matute, Ronald. “Oscar Arias con fuerte imagen”. La Nación, 29 de setiembre de 1998, <http:// wvw.nacion.com/ln_ee/1998/septiembre/29/pais1.html>.

Municipalidad de Heredia, Actas de la Sesión Extraordinaria - Solemne 352-2010, 17 de marso de 2010.

Pérez Brignoli, Héctor. Historia Contemporánea de Costa Rica. México: Fondo de cultura Económica, 1997.

Pérez Sáenz, Rocío. “Oscar Arias entregó su Declaración de Bienes”. La Prensa Libre, 1 de octubre de 2005, <http://www.prensalibre.co.cr/2005/octubre/01/economia06.php>.

“Reelección empezó con el azúcar...". Periódico Ojo, 7 de febrero del 2001, 3.

Ramírez, Alexander. "Calderón duda de Pacheco". La Nación, 6 de febrero del 2001, <http:// wVw.nacion.com/ln_ee/2001/febrero/06/pais2.html>.

Ramírez, Ximena. "Plan para recuperar la lógica de la economía campesina". Entrevista de Ximena Ramírez al Dr. Orlando Núñez, <http://www.euram.com.ni/pverdes/ Entrevista/orlando_nunez_136.htm>.

Registro Nacional de Costa Rica. Personería jurídica: Tomo n. ${ }^{\circ}$ 42, folio 444 y asiento 16.597.

Registro Nacional de Costa Rica. Personería jurídica: Tomo n. ${ }^{\circ}$ 67, folio 183 y asiento 119.

Registro Nacional de Costa Rica. Personería jurídica: Tomo n. ${ }^{\circ}$ 74, folio 556 y asiento 549.

Registro Nacional de Costa Rica. Personería jurídica: Tomo n. ${ }^{\circ} 77$, folio 331 y asiento 200.

Registro Nacional de Costa Rica. Personería jurídica: Tomo n. ${ }^{\circ}$ 108, folio 531 y asiento 434. 
Registro Nacional de Costa Rica. Personería jurídica: Tomo n. ${ }^{\circ}$ 135, folio 572 y asiento 453. Registro Nacional de Costa Rica. Personería jurídica: Tomo n. ${ }^{\circ}$ 277, folio 217 y asiento 180. Registro Nacional de Costa Rica. Personería jurídica: Tomo n. ${ }^{\circ} 328$, folio 136 y asiento 116.

Registro Nacional de Costa Rica. Personería jurídica: Tomo n. ${ }^{\circ}$ 475, folio 271 y asientos 203-204.

Rodríguez Chaverri, Camilo. "José Miguel Corrales: Fracción es una vagabunda". Periódico Ojo, 29 de agosto del 2002, 6.

Ruiz Centeno, Antonio. "Prometedora la ganadería en la provincia de Guanacaste". La Nación, 6 de noviembre de 1964, 41.

Rossi, Jorge. La traición de los "leales". San José, Costa Rica: Editorial de la Universidad Estatal a Distancia, 2002.

Segnini, Giannina; Rivera, Ernesto y Herrera, Mauricio. “Desconfianza en el PUSC motivó estructura paralela". La Nación, 22 de agosto del 2003, <http://wvw.nacion.com/ ln_ee/2003/agosto/22/pais2.html\#2112495>.

SEPSA. Política Agropecuaria 1987-1990 "Un diálogo permanente". Principales acciones a realizar. San José, Costa Rica: SEPSA, 1987.

Subirós Ruiz, Fermín. El cultivo de la caña de azúcar. San José, Costa Rica: Editorial de la Universidad Estatal a Distancia, 2000.

Tribunal Supremo de Elecciones. Donaciones al Partido Liberación Nacional. Año 2005. San José, Costa Rica: TSE, 2005.

Urbina, Alejandro. "Arias pedirá expulsión de Figueres del PLN". La Nación, 27 de octubre del 2004, <http://wvw.nacion.com/ln_ee/ESPECIALES/ice-alcatel/n1027.html>.

Urbina Pinto, Bernal. "Rodolfo Robles Guzmán”. La Nación, 12 de octubre de 1981, 11A.

Vargas, Alejandro. "Arias: pacto contra la reelección", La Nación, 14 de mayo del 2000, <http:// wvw.nacion.com/ln_ee/2000/mayo/14/pais3.html>.

Venegas, Ismael. "Asamblea aun más fraccionada para su último año". La Nación, 16 de mayo del 2005, <http://wvw.nacion.com/ln_ee/2005/mayo/16/pais1.html>.

Venegas, Ismael y Villalobos, Carlos. "Pedirán explicación a Guido Sáenz y Oscar Arias por libro". La Nación, 21 de enero del 2004, <http://wvw.nacion.com/ln_ee/2004/ enero/21/pais4.html>.

Zeitlin, Irving. Ideología y teoría sociológica. Buenos Aires, Argentina: Amorrortu, 2001.

Jorge Marchena Sanabria. Costarricense. Máster en Historia Aplicada con énfasis en Historia del Poder y Control Social de la Universidad Nacional. Docente de la Sede de Occidente e Investigador del Centro de Investigación en Identidad y Cultura Latinoamericana de la Universidad de Costa Rica.

Contacto: jorge.marchena@ucr.ac.cr 
